\title{
NMR Investigation and Conformational Analysis of a Synthetic Hexasaccharide
}

\author{
Monika Hiegemann \\ Ruhr-Universität Bochum, Lehrstuhl für Strukturchemie, Postfach 102148, \\ D-44780 Bochum, Germany \\ Helmut Duddeck* \\ Universität Hannover, Institut für Organische Chemie, Schneiderberg $1 \mathrm{~B}$, \\ D-30167 Hannover, Germany
}

Richard R. Schmidt, Alexander Toepfer**

Fakultät für Chemie, Universität Konstanz, Postfach 5560 M725,

D-78434 Konstanz, Germany

Z. Naturforsch. 50b, $1091-1095$ (1995); received Februay 2, 1995

Saccharides, Conformational Analysis, NMR Spectra, Hexasaccharide

The structure of the hexasaccharide $\mathbf{1}$ has been examined by a spectroscopic investigation using one- and two-dimensional NMR spectroscopy. All ${ }^{1} \mathrm{H}$ and ${ }^{13} \mathrm{C}$ signals of the saccharide part were assigned. NOESY and ROESY experiments allowed to discuss the flexibility of the molecule.

\section{Introduction}

The hexasaccharide (1) which is a decisive precursor in our synthesis of the Lewis antigen $\mathrm{X}$ $\left(\mathrm{Le}^{x}\right)$ family of glycosphingolipids $[1,2]$ carries a large number of protecting groups, namely benzyl, acetyl, tert-butyldimethylsilyl (TBDMS) and azido groups. We were interested in confirming the structure of $\mathbf{1}$, assigning the NMR spectra and providing information about the dynamics of the molecule.

\section{Results and Discussion}

\section{Signals assignments and interglycosidic linkages}

${ }^{1} \mathrm{H}$ and ${ }^{13} \mathrm{C}$ signal assignments of the monosaccharide units were made by a combined interpretation of selective INEPT and all 2D spectra. Here, it was of particular help that the configuration of the six monosaccharides was already known; ${ }^{1} \mathrm{H}$ signal splittings (Table I) could be interpreted in terms of the stereochemical position of the hydrogen atoms proving the sugar identities.

\footnotetext{
* Reprint requests to Prof. Dr. H. Duddeck.

** Present address: Hoechst AG, Hauptlabor D 830, D-64926 Frankfurt am Main.
}

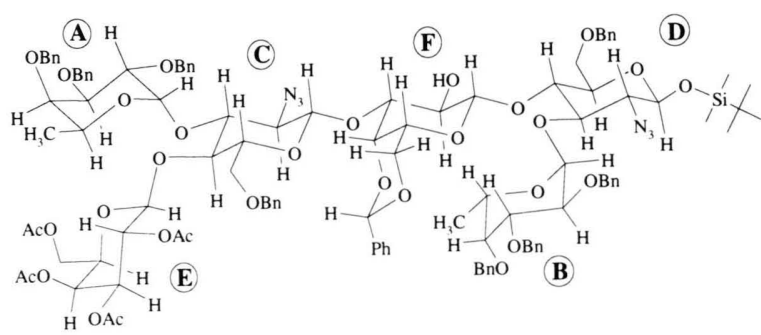

Scheme 1. a The encircled letters indicating the individual monosaccharide units have been assigned according to the sequence of the anomeric proton signals in the ${ }^{1} \mathrm{H}$ NMR spectrum ( $c f$. Table I). They are (ignoring the attached protecting groups): $\alpha$-D-fucose (A and $\mathbf{B}), 2$ azido-2-deoxy- $\beta$-D-glucose $(\mathbf{C}$ and $\mathbf{D})$, and $\beta$-D-galactose $(\mathbf{E}$ and $\mathbf{F})$.

An example may illustrate the assigning procedure for the individual monosaccharide subunits: the ${ }^{1} \mathrm{H}$ and ${ }^{13} \mathrm{C}$ chemical shifts in the anomeric $\mathrm{CH}$ fragment as well as the coupling constants ${ }^{3} J(\mathrm{H}-1, \mathrm{H}-2)$ and ${ }^{1} J(\mathrm{C}-1, \mathrm{H}-1)$ indicated the configuration at the anomeric carbon atoms. The ${ }^{1} \mathrm{H}{ }^{1} \mathrm{H}$ COSY and ${ }^{1} \mathrm{H}^{1} \mathrm{H}^{1} \mathrm{H}$ RELAY spectra afforded the proton connectivities of all protons. A difficulty arose only in the case of the two fucoses $\mathbf{A}$ and $\mathbf{B}$; it had to be decided which of the methyl-proton/ $\mathrm{H}-5$ fragments belonged to which $\mathrm{H}-1-$ to- $\mathrm{H}-4$ fragment; for the assignment see below. Inspecting the ${ }^{1} \mathrm{H}{ }^{13} \mathrm{C}$ COSY spectra the carbon signals of $\mathrm{C}-1$

0932-0776/95/0700-1091\$06.00 (C) 1995 Verlag der Zeitschrift für Naturforschung. All rights reserved. 


\begin{tabular}{|c|c|c|c|c|c|c|c|}
\hline & & $\delta\left({ }^{1} \mathrm{H}\right)$ & ${ }^{3} J(\mathrm{H} . \mathrm{H})$ & & & $\delta\left({ }^{1} \mathrm{H}\right)$ & ${ }^{3} J(\mathrm{H} . \mathrm{H})$ \\
\hline $\mathbf{A}$ & 1 & 5.53 & d. 3.8 & B & 1 & 5.38 & d. 3.2 \\
\hline \multirow[t]{5}{*}{$\alpha 1 \rightarrow \mathrm{C} 3$} & 2 & 4.08 & dd. $(4 ; 8)$ & $\alpha 1 \rightarrow \mathrm{D} 3$ & 2 & 3.84 & dd. $(4 ; 8)$ \\
\hline & 3 & 3.85 & & & 3 & 3.82 & \\
\hline & 4 & 3.62 & $<1$ & & 4 & 3.09 & $<1$ \\
\hline & 5 & 4.62 & & & 5 & 4.68 & \\
\hline & 6 & 1.22 & d. 6.5 & & 6 & 0.95 & 6.5 \\
\hline & 1 & 4.96 & d. 8.0 & D & 1 & 4.53 & d. 7.3 \\
\hline \multirow{6}{*}{$\beta 1 \rightarrow \mathrm{F} 3$} & 2 & 3.63 & t. $(8 ; 8)$ & $\beta 1 \rightarrow$ OTBDMS & 2 & 3.46 & t. $(8 ; 8)$ \\
\hline & 3 & 3.55 & t. $(8 ; 8)$ & & 3 & 3.41 & t. $(8 ; 8)$ \\
\hline & 4 & 3.91 & & & 4 & 4.05 & t. $(8 ; 8)$ \\
\hline & 5 & 3.25 & & & 5 & 3.30 & \\
\hline & 6 & 3.63 & & & 6 & 3.64 & \\
\hline & $6^{\prime}$ & 3.73 & & & $6^{\prime}$ & 3.99 & \\
\hline $\mathbf{E}$ & 1 & 4.51 & d. 8.2 & $\mathbf{F}$ & 1 & 4.47 & d. 6.8 \\
\hline \multirow[t]{6}{*}{$\beta 1 \rightarrow \mathrm{C} 4$} & 2 & 5.03 & t. $(8 ; 8)$ & $\beta 1 \rightarrow \mathrm{D} 4$ & 2 & 3.86 & t. $(8 ; 8)$ \\
\hline & 3 & 4.64 & dd. $(4 ; 8)$ & & 3 & 3.60 & dd. $(4 ; 8)$ \\
\hline & 4 & 5.14 & dd. $(0.8 ; 3.5)$ & & 4 & 4.14 & \\
\hline & 5 & 3.42 & td. $(2 ; 6 ; 8)$ & & 5 & 3.03 & \\
\hline & 6 & 3.82 & & & 6 & 3.93 & \\
\hline & $6^{\prime}$ & 4.03 & & & $6^{\prime}$ & 4.25 & \\
\hline
\end{tabular}

\begin{tabular}{|c|c|c|c|c|c|c|c|}
\hline & & $\delta\left({ }^{13} \mathrm{C}\right)$ & ${ }^{1} J(\mathrm{C} . \mathrm{H})$ & & & $\delta\left({ }^{13} \mathrm{C}\right)$ & ${ }^{1} J(\mathrm{C} . \mathrm{H})$ \\
\hline$\alpha 1 \stackrel{\mathbf{A}}{\rightarrow} \mathrm{C} 3$ & $\begin{array}{l}1 \\
2 \\
3 \\
4 \\
5 \\
6\end{array}$ & $\begin{array}{l}97.4 \\
75.5 \\
79.9 \\
76.8 \\
66.1 \\
16.7\end{array}$ & 169 & $\alpha \stackrel{\mathbf{B}}{\rightarrow} \mathrm{D} 3$ & $\begin{array}{l}1 \\
2 \\
3 \\
4 \\
5 \\
6\end{array}$ & $\begin{array}{l}97.7 \\
75.1 \\
78.9 \\
78.9 \\
66.0 \\
16.2\end{array}$ & 170 \\
\hline$\underset{\beta 1 \rightarrow \text { F } 3}{\mathbf{C}}$ & $\begin{array}{l}1 \\
2 \\
3 \\
4 \\
5 \\
6\end{array}$ & $\begin{array}{r}102.3 \\
66.1 \\
74.3 \\
73.8 \\
75.0 \\
68.1\end{array}$ & 161 & $\beta 1 \stackrel{\text { D }}{\rightarrow}$ OTBDMS & $\begin{array}{l}1 \\
2 \\
3 \\
4 \\
5 \\
6\end{array}$ & $\begin{array}{l}97.6 \\
68.8 \\
74.8 \\
73.6 \\
75.6 \\
67.6\end{array}$ & 160 \\
\hline$\stackrel{\mathbf{E}}{\beta} \underset{\mathrm{C} 4}{ }$ & $\begin{array}{l}1 \\
2 \\
3 \\
4 \\
5 \\
6\end{array}$ & $\begin{array}{r}104.1 \\
68.7 \\
70.7 \\
66.5 \\
70.2 \\
60.0\end{array}$ & 159 & $\underset{\beta 1 \stackrel{\mathbf{F}}{\rightarrow} \mathrm{D} 4}{ }$ & $\begin{array}{l}1 \\
2 \\
3 \\
4 \\
5 \\
6\end{array}$ & $\begin{array}{r}101.5 \\
70.4 \\
78.9 \\
75.9 \\
66.5 \\
69.2\end{array}$ & 162 \\
\hline
\end{tabular}

Table I. ${ }^{1} \mathrm{H}$ chemical shifts ${ }^{\mathrm{a}}$ and coupling constants (in $\mathrm{Hz})^{\mathrm{b}}$ of $\mathbf{1},{ }^{\mathrm{c}}$ in $\mathrm{CDCl}_{3}$.

\begin{abstract}
${ }^{\text {a }}$ Further signals: $\mathrm{C}\left(\mathrm{CH}_{3}\right)_{3}$ : $\delta=0.92 ; \operatorname{Si}\left(\mathrm{CH}_{3}\right)_{2}: \delta=0.15$ and 0.14 ; Ac: $\delta=1.99,1.92$, 1.92, and 1.74; $\mathrm{PhCH}: \delta=$ 5.56; $\mathrm{CH}_{2}$ of benzyl: $\delta=5.0$ 4.0 ; aromatic protons: $\delta=$ $7.5-7.0 ;{ }^{\mathrm{b}}$ coupling constants in brackets were estimated from ${ }^{1} \mathrm{H}{ }^{1} \mathrm{H}$ COSY experiments; ${ }^{\mathrm{c}}$ for the identity of the monosaccharide subunits and their abbreviations see foot-
\end{abstract} note of Scheme 1.

Table II. ${ }^{13} \mathrm{C}$ chemical shifts ${ }^{\mathrm{a}}$ and coupling constants (in $\mathrm{Hz}$ ) of 1, in $\mathrm{CDCl}_{3}$.

\begin{abstract}
${ }^{\text {a }}$ Further signals: $\mathrm{C}\left(\mathrm{CH}_{3}\right)_{3}$ : $\delta=18.0 ; \mathrm{C}\left(\underline{\mathrm{CH}}_{3}\right)_{3}: \bar{\delta}=25.6$; $\mathrm{Si}\left(\mathrm{CH}_{3}\right)_{2}: \quad \frac{\mathrm{C}}{\delta}=-4.9$; $\mathrm{O}(\underline{\mathrm{C}} \mathrm{O}) \mathrm{CH}_{3}: \delta=169.9,169.7$, and 168.6; $\mathrm{O}(\mathrm{CO}) \mathrm{CH}_{3}: \delta=$ 20.6, 20.5, and 20.45; $\mathrm{PhCH}$ : $\delta=99.9 ; \mathrm{CH}_{2}$ of benzyl: $\delta=$ 74.9-71.8; aromatic carbons: $\delta=128.7-125.7(\mathrm{CH}) ; \delta=$ 139.5-137.3 (C); ${ }^{\mathrm{b}}$ for the identity of the monosaccharide subunits and their abbreviations see footnote of Scheme 1.
\end{abstract}

to C-6 could be assigned as well, again with the exception of the methyl and C-5 carbons of both fucoses. The above mentioned problem was solved by a selective INEPT experiment (Figure 1): irradiation of the anomeric proton of monosaccharide B (B 1) afforded responses of C-3 and C-5 of sugar B (B 3 and B 5, respectively), as well as D 3 .

In a few critical cases, for example the anomeric protons D 1 and E1, with very similar ${ }^{1} \mathrm{H}$ chemical shifts, the assignment taken from the 2D COSY and RELAY spectra were confirmed by additional 1D COSY experiments.

The basic experiment to establish interglycosidic linkages was the selective INEPT experiment as illustrated in Fig. 1. Polarization transfer (PT) is possible via of the ${ }^{3} J(\mathrm{COCH})$ coupling from the anomeric proton (here: B 1) to the carbon of the other monosaccharide unit (here: D3) across the glycosidic linkage. Thereby, the pairwise identification of the glucose, fucose and galactose units, 


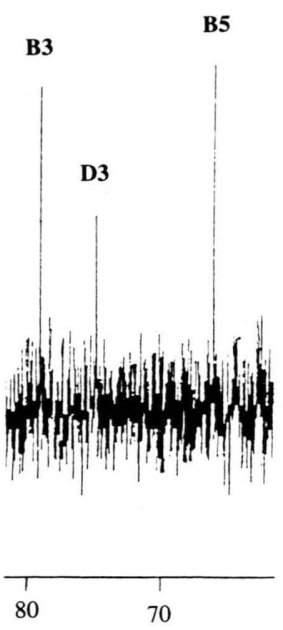

Fig. 1. Selective $\left\{{ }^{1} \mathrm{H}\right\}^{13} \mathrm{C}$ INEPT experiment; irradiation on the anomeric proton $\mathrm{B} 1$.

respectively, could be achieved unequivocally. It should be noted that in the case of the galactose pair $(\mathbf{E}$ and $\mathbf{F})$ a differentiation was already possible by simple acetylation arguments and by the detection of a ${ }^{3} J(\mathrm{HCOH})$ coupling in $\mathbf{F}$. (In contrast to $\mathbf{E}, \mathbf{F}$ has a free hydroxyl group.) D 1 and E1 could not be irradiated separately with sufficient amplitude. However, since $\mathbf{D}$ is the terminal sugar, the only response observed (C4) must be from the PT E $1 \rightarrow \mathrm{C} 4$. All results of the selective INEPT experiments are depicted by dashed arrows in Fig. 2.

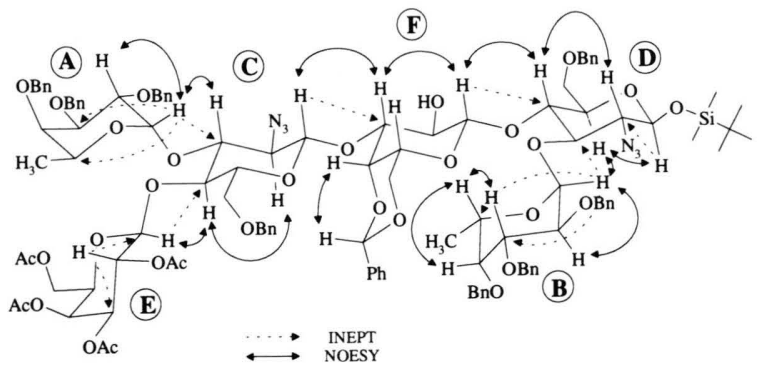

Fig. 2. Results of selective INEPT and NOESY experiments.

The ${ }^{1} \mathrm{H}$ and ${ }^{13} \mathrm{C}$ signals of most methylenes in the eight benzyl groups are very close. Similarly, the methyl and carbonyl signals of the four acetyl groups are very difficult to differentiate. So, we refrained from an individual assignment.

\section{Conformational analysis}

As expected the six monosaccharide subunits adopt chair conformations as indicated in

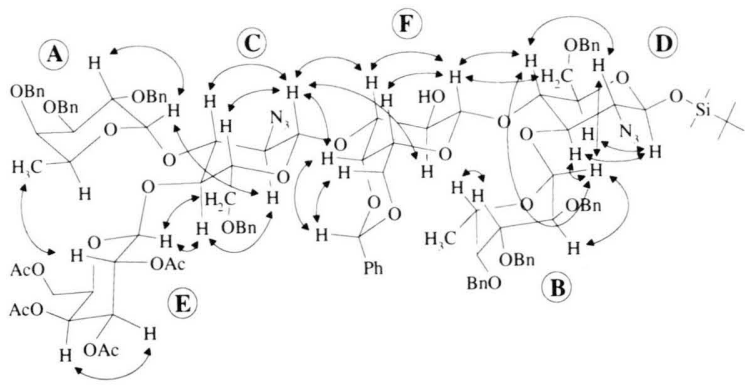

Fig. 3. Results of the ROESY experiment.

Scheme 1. In this part of our investigation NOESY and ROESY experiments were most important. We prefered ROESY because of the overall-motional behaviour of the molecule 1. NOE-induced signal enhancement in the NOESY experiments were often small and difficult to detect [3]. NOESY results are summarized in Fig. 2 (solid double arrows) and ROESY results in Fig. 3.

Our experiments afforded information about the spatial proximities of certain hydrogen atoms; we assume that the distances are $\leq 3.5$ Angström so that it was possible to estimate areas of torsional angles $\Phi$ and $\psi$ across the interglycosidic linkages [4] (for the definition of $\Phi$ and $\psi$ see structures in Table III). The structures in the Figures 2 and 3 are based on the results of these qualitative interpretations, as far as they were reliable enough.

In order to confirm these results we tried to perform MM2 calculations (personal computer version) with a double dihedral angle driver for the torsional angles at the interglycosidic bonds, how-

Table III. Areas of torsional angles $\Phi$ and $\psi$ calculated by MM2 calculations.

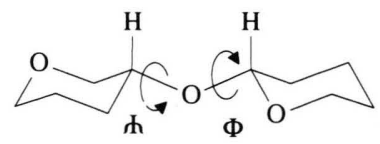

\begin{tabular}{lll}
\hline & $\Phi\left[{ }^{\circ}\right]$ & $\psi\left[{ }^{\circ}\right]$ \\
\hline D-B: & 55 to 60 & 40 to 45 \\
D-F: & 50 to 55 & 15 to 20 \\
F-C: $(2$ minima) & 55 to 60 & 5 to 10 \\
& ca. 25 & ca. -45 \\
C-A: & 55 to 60 & ca. 35 \\
C-E: & 45 to 50 & 10 to 15 \\
\hline
\end{tabular}


ever, without any modelling of the medium. In a first step we optimized the conformations of the monosaccharide unit including the respective protecting groups. Then, two trisaccharide substructures $(\mathbf{A}-\mathbf{C}-\mathbf{E}$ and $\mathbf{F}-\mathbf{D}-\mathbf{B})$ were constructed and refined. Finally, the optimized trisaccharide fragments were combined and again recalculated. Of course, we are well aware that the value of such models is rather limited.

For three glycosidic bonds $(\mathbf{A}-\mathbf{C}, \mathbf{E}-\mathbf{C}$ and F-D) we obtained NOE responses which were consistent with the existence of one single preferred conformation. The calculated torsional angles confirmed theses conformations. For the bond $\mathbf{C}-\mathbf{F}$ we found ROESY (NOESY) signals which are not compatible with one single minimum-energy conformation; we observed contacts between $\mathrm{C} 1$ and $\mathrm{F} 2$ but also between $\mathrm{C} 1$ and $\mathrm{F} 3$. The MM 2 results confirm this finding by affording two energy minima with a difference of only $1.7 \mathrm{~kJ} / \mathrm{mol}$. These two minima (Table III) fit nicely to the spectral evidences. In addition, there were ROESY signals indicating more than one minimum-energy conformation for the $\mathbf{D}-\mathbf{B}$ bond; contacts between B1 and D2, B 1 and D 4 on one hand, but between B 1 and D 3 on the other. Here, however, we calculated only one energy minimum with a rather large $\psi$ angle as compared to the $\mathbf{A} / \mathbf{C}$ moiety with the same junction of the same sugars.

Summarizing, we assume that the central glycosidic bond $(\mathbf{C}-\mathbf{F})$ is not rigid other than the bonds $\mathbf{D}-\mathbf{F}, \mathbf{C}-\mathbf{E}$ and $\mathbf{C}-\mathbf{A}$. Sugar $\mathbf{B}$ is rather flexible in contrast to the other terminal sugars $\mathbf{A}$ and $\mathbf{E}$. We suspect that the large $\psi$ angle in the $\mathbf{D}-\mathbf{B}$ bond and the flexibility of the $\mathbf{C}-\mathbf{F}$ bond are due to steric interference between the annelated O-benzylidene group attached to $\mathbf{F}$ and $\mathbf{B}$ or $\mathbf{C}$, respectively.

\section{Experimental}

The synthesis of tert-butyldimethylsilyl-O(2,3,4,6-tetra-O-acetyl- $\beta$-D-galactopyranosyl)$(1 \rightarrow 4)$-[(2,3,4-tri-O-benzyl- $\alpha$-L-fucopyranosyl)$(1 \rightarrow 3)$ ]-(2-azido-6-O-benzyl-2-deoxy- $\beta$-D-

glucopyranosyl)-( $1 \rightarrow 3)-(4,6-O-b e n z y l i d e n e-~ \beta$-Dgalactopyranosyl)-( $1 \rightarrow 4)$-[2,3,4-tri-O-benzyl] $\alpha$-Lfucopyranosyl)-(1 $\rightarrow 3)]$-2-azido-6-O-benzyl-2deoxy- $\beta$-D-glucopyranoside (1) has been published previously [2]; $\mathbf{1}$ was obtained as crystalline material.
For the NMR investigation described here, compound 1 was dissolved in $\mathrm{CDCl}_{3}$ in a ca. $0.05 \mathrm{mmo-}$ lar concentration. NMR spectra were recorded using a 5-mm-NMR-tube on a Bruker AM-400 equipped with a dual-probe-head $\left({ }^{1} \mathrm{H}: 400.1 \mathrm{MHz}\right.$ and ${ }^{13} \mathrm{C}: 100.6 \mathrm{MHz}$ ) and a selective-excitationunit.

\section{$1 \mathrm{DNMR}$ experiments}

${ }^{1} \mathrm{H}$ NMR, spectral width $4000 \mathrm{~Hz}, 32 \mathrm{~K}$ data point, digital resolution $0.24 \mathrm{~Hz} /$ point. Selective $1 \mathrm{D}$ COSY and RELAY using Gaussian, shaped pulses [5] (pulse sequence: standard Bruker software), spectral width and digital resolution were the same as in a normal ${ }^{1} \mathrm{H}$ spectrum. ${ }^{1} \mathrm{H}$ broadband decoupled ${ }^{13} \mathrm{C}$ NMR and DEPT (standard Bruker software and parameters): spectral width $25000 \mathrm{~Hz}, 32 \mathrm{~K}$ data point, digital resolution 1.5 $\mathrm{Hz} /$ point; ${ }^{1} \mathrm{H}$-gated-decoupled ${ }^{13} \mathrm{C}$ NMR: spectral width covering only the area of saccharide signals, digital resolution $0.53 \mathrm{~Hz} /$ point. Selective INEPT experiment: optimized to $J\left({ }^{13} \mathrm{C},{ }^{1} \mathrm{H}\right)=6 \mathrm{~Hz}$, irradiation of anomeric protons with selective pulses via the ${ }^{1} \mathrm{H}$-decoupler $\left(180^{\circ}\right.$-pulse duration: $\pi=$ $1 /(4 \Delta v)=20 \mathrm{msec}$ with $\Delta v=12.5 \mathrm{~Hz})$.

\section{$2 D N M R$ experiments}

${ }^{1} \mathrm{H},{ }^{1} \mathrm{H}$ COSY and ${ }^{1} \mathrm{H},{ }^{1} \mathrm{H},{ }^{1} \mathrm{H}$ RELAY (standard Bruker software and parameters): recorded with spectral widths of 1000 to $1200 \mathrm{~Hz}$ (area of saccharide signals only) with additional presaturation of the water signal. Data matrix: $1 \mathrm{~K} \times 2 \mathrm{~K}(512 \mathrm{ex}-$ periments with $512 \mathrm{~W}$ zero filling in $\mathrm{F} 1,2 \mathrm{~K}$ data points in F2); digital resolution: $1.083 \mathrm{~Hz} /$ point (for a $1108 \mathrm{~Hz}$ spectral width) in F2, 16 transients in each experiment. NOESY (standard pulse sequence): mixing time $300 \mathrm{~ms}$, relaxation delay 3.5 s, data matrix $2 \mathrm{~K} \times 2 \mathrm{~K}(512$ experiments with $2 \mathrm{~K}$ zero filling in $\mathrm{F} 1,2 \mathrm{~K}$ data point in $\mathrm{F} 2$ ); digital resolution $3.4 \mathrm{~Hz} /$ point in $\mathrm{F} 2$ with a spectral width of $3472 \mathrm{~Hz}$ and 32 transients in each experiment. ROESY [6] (standard pulse sequence): spin-lock time in different experiments 80, 120, 160, 250, 300 and $400 \mathrm{~ms}$ (optimal results with $300 \mathrm{~ms}$ ), relaxation delay $3.5 \mathrm{~s}$, data matrix and digital resolution were identical with NOESY experiments. ${ }^{1} \mathrm{H},{ }^{13} \mathrm{C}$ COSY (area of saccharide signals only, standard Bruker software and parameters): optimized to $J\left({ }^{13} \mathrm{C},{ }^{1} \mathrm{H}\right)=140 \mathrm{~Hz}$, data matrix $1 \mathrm{~K} \times 2 \mathrm{~K}$ (128 experiments to $1 \mathrm{~K}$ zero filling in $\mathrm{F} 1,2 \mathrm{~K}$ in F2), digital resolution $8.7 \mathrm{~Hz} /$ point in $\mathrm{F} 1$ and 4.4 $\mathrm{Hz}$ /point in F2, 256 transients in each experiment.

Force-field calculations were performed using a standard MM2 program (PC version). 


\section{Acknowledgement}

This work was supported by the Deutsche Forschungsgemeinschaft and the Fonds der Chemischen Industrie.

[1] a) R. R. Schmidt, A. Toepfer, Tetrahedron Lett. 32, 3353 (1991);

b) A. Toepfer, R. R. Schmidt, Tetrahedron Lett. 33, 5161 (1992).

[2] A. Toepfer, W. Kinzy, R. R. Schmidt, Liebigs Ann. Chem. 449 (1994).

[3] D. Neuhaus, M. P. Williamson, The Nuclear Overhauser Effect in Structural and Conformational Analysis, VCH, New York (1989).

[4] A. S. Shashkov, G. M. Lipkind, Y. A. Knirel, N. K. Kotchetkov, Magn. Reson. Chem. 26, 735 (1988).
[5] H. Kessler, H. Oschkinat, C. Griesinger, W. Bermel, J. Magn. Reson. 70, 106 (1986).

[6] a) A. A. Bothner-By, R. L. Stevens, J. Lee, C. D. Warren, R. W. Jeanloz, J. Am. Chem. Soc. 106, 811 (1984);

b) A. Bax, D. G. Davis, J. Magn. Reson. 63, 207 (1985);

c) H. Kessler, M. Gehrke, C. Griesinger, Angew. Chem. 100, 507 (1988); Angew. Chem., Int. Ed. Engl. 27, 490 (1988). 